\title{
DESIGN AND ANALYSIS OF QUASI CASCADED MULTI-LEVEL INVERTER
}

\author{
T.Sakthivel \\ PG Scholar, Power Electronics and Drives, Government College of Engineering, Salem, \\ Tamilnadu, India \\ Dr.C. Govindaraju \\ Assistant professor, Electrical and Electronics Engineering, Government College of \\ Engineering, Salem, Tamilnadu, India
}

\begin{abstract}
This paper presents new topology of Quasi multi-level inverter (MLI) with five level output voltage. Traditional cascaded MLI is a buck DC-AC conversion circuit, which puts a limit on the peak AC voltage. However, within the proposed converter a shoot through state is implemented to increase the output voltage. The number of passive components used in the circuit is less, thereby reducing size, cost and weight. The voltage unbalance problem is prevented by using a low voltage capacitor between the two full bridge outputs. The capacitor voltage of each module is organized with a PI controller to generate the switching pulses for switches of the proposed structure. Simulation results are added to examine the feasibility.
\end{abstract}

Keywords: Boost inverter, Cascaded Multilevel inverter, and quasi-Z-source inverter

Cite this Article: T.Sakthivel, and Dr.C. Govindaraju, Design And Analysis Of Quasi Cascaded Multi-Level Inverter, International Journal of Electrical Engineering \& Technology, 10(2), 2019, pp. 13-23.

http://iaeme.com/Home/issue/IJEET?Volume $=10 \&$ Issue $=2$

\section{INTRODUCTION}

Multilevel inverters (MLI) are so popular attentions from scholars because of their blessings of improved satisfactory output waveforms with decrease fashionable Total Harmonic Distortion (THD), smaller filter size and lessor electromagnetic interface (EMI) [1]. Some of the basic multilevel inverter topologies are flying capacitors, neutral point clamped (NPC), and Cascaded Multilevel Inverters (CMI). Among those topologies, the CMI has more popular due to modularity and its contribution of excessive power. It makes the CMI an appealing choice for applications including uninterruptible power supplies (UPS), grid-connected system, Statcom and motor drive [2-4].

The conventional cascaded multilevel inverter is a stepdown DC-AC energy conversion, in which the peak AC output voltage is restrained through the DC voltages. In [5] an extra DC$\mathrm{DC}$ boost converter is added for every module within the CMI topology to attain the excessive AC output voltage while the DC input voltages are low. Adding DC-DC boost power converter 
consequences in low efficiency and excessive price. Two capacitors, two enhance inductors, two diodes, ten switches, filter inductor used in the conventional CHB-BFLI.

DC-link voltage on each full bridge circuit can be controlled using boost converter. Short circuit in the DC source can be avoided by inducing a dead time between two switches in a leg [6]. Singlestage power conversion in a cascaded ZSI was proposed in [7]. The number of the ST states in the single-phase Single Bridge Inverter (SBI) is two in one switching period. Therefore, the switching frequencyof the inductors are half of the operating frequency. In cascaded ZSI, the input DC current possess less ripple and hence continuous. The same DClink voltage can be producing by controlling the ST duty cycle in each module of cascaded ZSI. The control of Three-phase cascaded ZSI's is demonstratedand proposed in [8].

Cascaded ZSI based PV power generation and energy storage system is proposed in [9]. Fault tolerant cascaded inverter using Z-sourced network are demonstrated in [10]. Design and simulation of cascaded transformer based multilevel inverter using single Z-source network is investigated in [11]. Dual-boost/buck converter used Active Cascaded Multilevel Inverter (ACMI) is proposed in [12]. Similar to cascaded ZSI, ACMI inverter also has the buck boost voltage and shoot-through immunity. Moreover, the cascaded ZSI and the ACMI inverter use a large number of passive elements with raising the cost, weight \&size of the cascaded system.

The Quasi Z Source (qZS) network is replaced by a quasi-switched boost (qSB) network [13]. On comparison of qZS network, the qSB network uses one less inductor, one less capacitor, one more switch and one more diode in front of the main full bridge circuit. The qSB network based isolated high step up DC-DC converter is proposed. In this paper, a new quasi cascaded full bridge five level boost inverter (qCFB-FLBI) in single stage is proposed. In the proposed CMI, the qSB network is used in each module.

This work proposes a quasi-cascaded five-level boost output with a phase shifted pulse width modulated scheme to control the non-shoot through and shoot through states of the inverter modules. The peak value of AC output can be boosted with the help of shoot through state. The quasi switched boost structure is used in the full Bridge modules that reduces the number of passive components at the same time increasing the shoot-through immunity.

The voltage imbalance problem while cascading the output voltages in full Bridge modules needs to be addressed. The structure of the converter is to be designed in a such a way that it aids the cascading of more than two full bridge modules to increase the output AC voltage's level obtained from the converter. The circuit needs to be analyzed using simulation for various loading conditions and the results are compared with conventional CMI to ensure that objective of the proposed converter.

\section{PROPOSED QUASI CASCADED MULTI LEVEL INVERTER}

The configuration of proposed single-stage Quasi cascaded multi-level inverter (QCMI) is presented in Fig.1.The proposed inverter contains two DC sources, an inductor filter in the output side and two quasi boost inverter (qBI). Single qBI module contains two diodes, four power switches, boost inductor and capacitor. The proposed QCMI has five levels in output voltage. It operates symmetrical and asymmetrical modes.

\subsection{Operating Principles}

Double qBI modules operates with same parameters, so module A is used to analyze the operating principle. Fig. 2 shows modes of operation of the qBI module A in the inverter. The switches $S_{1}$ and $S_{2}$ are turned onin the Shoot-Through (ST) state 1, as shown in Fig. 2(a), $D_{A 1}$ is conducting, while $\mathrm{D}_{\mathrm{A} 2}$ is blocking. 
The output voltage of the qBI module $A$ is $-V_{C A}$ when the switch $S_{3}$ is on otherwise it is zero. The inductor $\mathrm{L}_{\mathrm{A}}$ is charged by the source.

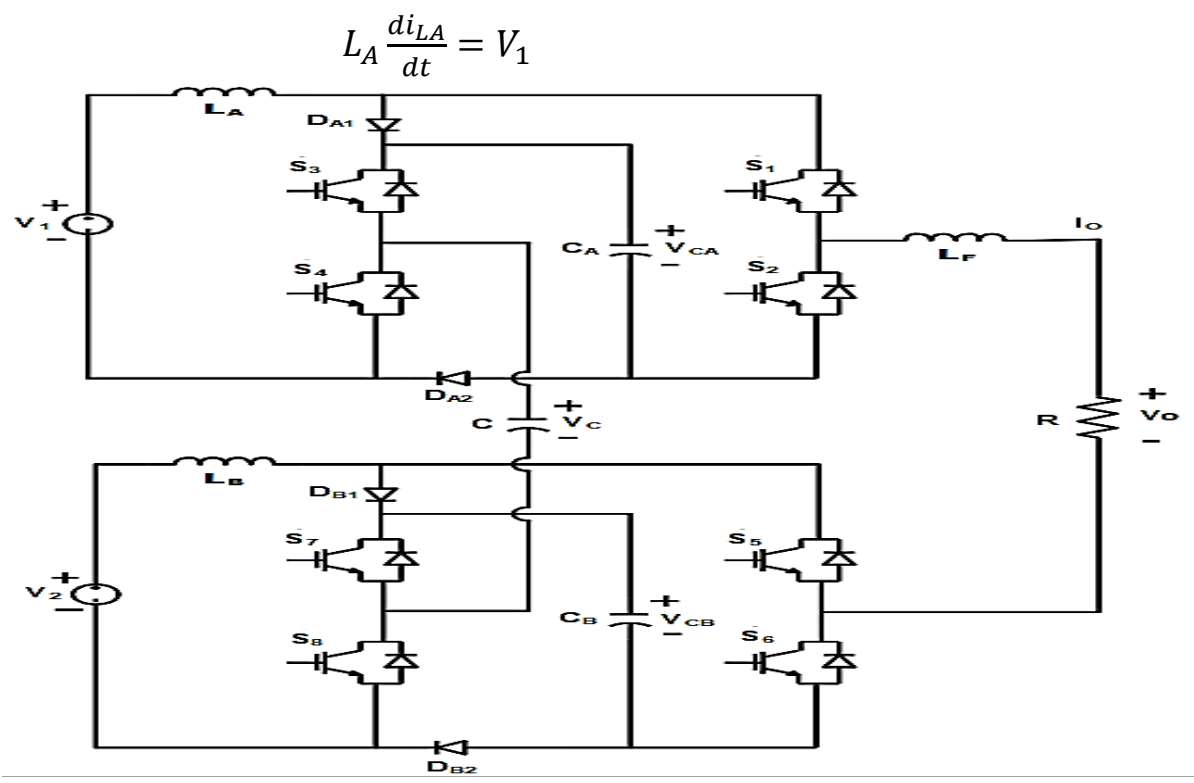

Figure 1 Proposed QCMI with Filter Capacitor.

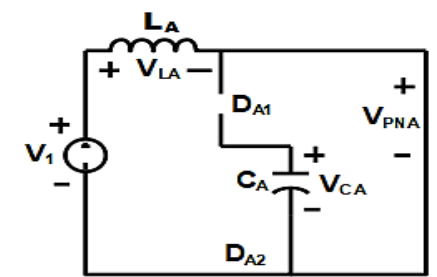

(a)

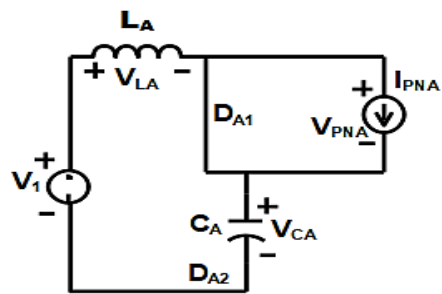

(c)

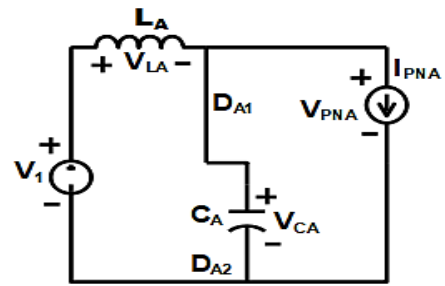

(e)

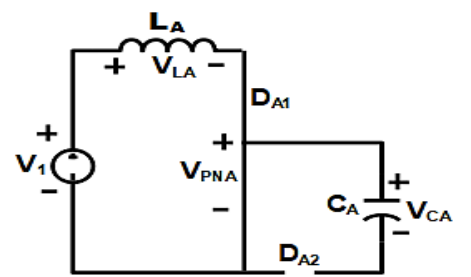

(b)

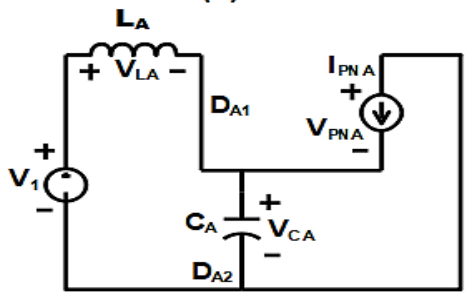

(d)

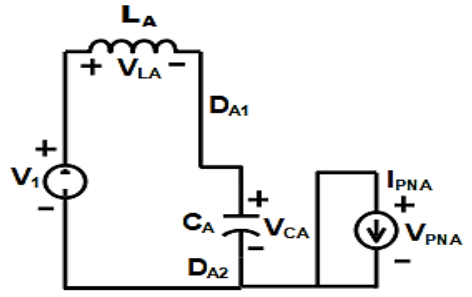

(f)

Figure 2 Modules operating states 1, (b) ST state 2, (c) NST state 1, (d) NST state 2, (e) NST state 3 and (f) NST state 4.

The switches $S_{2}$ and $S_{3}$ are turned on in the NST state 2, as shown in Fig. 2(d), The qBI module A output voltage is $-\mathrm{V}_{\mathrm{CA}}$. The switches $\mathrm{S}_{1}$ and $\mathrm{S}_{4}$ are turned onin the NST state 3 , as shown in Fig. 2(e), The qBI module A output voltage is $\mathrm{V}_{\mathrm{CA}}$. During the non-Shoot through (NST) states as shown in Figs. 2(c)-2(f), $\mathrm{D}_{\mathrm{A} 1}$ and $\mathrm{D}_{\mathrm{A} 2}$ are conducting. The capacitor $\mathrm{C}_{\mathrm{A}}$ is 
charged from $\mathrm{V}_{1}$, while the inductor $\mathrm{L}_{\mathrm{A}}$ transfers energy from the DC voltage source to the main circuit. The full bridge circuit is equivalent as a current source, ipNA.

$$
L_{A} \frac{d i_{L A}}{d t}=V_{1}-V_{C A}
$$

In one switching period, T, each leg has twice short circuits alternatively. From (1) and (2), volt-sec balance equation is

$$
\bar{V}_{L A}=\left[1-2 \frac{T_{0}}{T}\right]\left(V_{1}-V_{C A}\right)+2 \frac{T_{0}}{T} V_{1}
$$

where $\mathrm{T}_{0} / \mathrm{T}=\mathrm{D}_{1}$, a ST duty ratio in each leg of module $\mathrm{A}, \mathrm{T}_{0}$ is total ST time intervals in one leg. The average inductor voltage should be zero in a steady state.

$$
V_{C A}=\frac{1}{1-2 T_{0} / T} V_{1}=\frac{1}{1-2 D_{1}} V_{1}
$$

Similarly, we also obtain the capacitor voltage on the module B as

$$
V_{C B}=\frac{1}{1-2 D_{2}} V_{2}
$$

\subsection{Modulation control of the proposed inverter}

For module $\mathrm{A}$, the control voltages, $-\mathrm{V}_{\mathrm{s}}$ and $\mathrm{V}_{\mathrm{s}}$ are compared to a high frequency carrier signal, $\mathrm{V}_{\mathrm{t} 1}$, produce control pulses for the $\mathrm{S}_{1}$ and $\mathrm{S}_{2}$ switches. The DC voltages, $\mathrm{V}_{\mathrm{SH}}$ and $-\mathrm{V}_{\mathrm{SH}}$, are compared with $V_{t 1}$ to produce the $S_{0 a}$ control pulse. Then $S_{0 a}$ is added to the control pulses of switches $S_{1}$ and $S_{2}$ to produce the ST states. Likewise, the $V_{t 1}$ is shifted by $90^{\circ}$ to create another high-frequency carrier signal, $\mathrm{V}_{\mathrm{t} 2}$. $\mathrm{V}_{\mathrm{s}}$ and $-\mathrm{V}_{\mathrm{s}}$ are compared with $\mathrm{V}_{\mathrm{t} 2}$ to produce control pulses for the $S_{3}$ and $S_{4}$ switches. $V_{S H}$ and $-V_{S H}$ are compared to the $V_{t 2}$ to produce $S_{0 b}$ control pulse. The $S_{0 b}$ is then added to the control pulses of switches $S_{3}$ and $S_{4}$ to produce the ST states. As a result, the output voltage $\mathrm{V}_{\mathrm{ab}}$ of the inverter module A contain three levels. Similar for the second inverter module, two control voltages $\left(\mathrm{V}_{\mathrm{s}}\right.$ and $\left.-\mathrm{V}_{\mathrm{s}}\right)$ are shifted in $180^{\circ}$ to produce output voltage $\mathrm{V}_{\mathrm{cb}}$ of the module $\mathrm{B}$.

The difference of $V_{a b}$ and $V_{c b}$ gives the output voltage $V_{a c}$ Fig. 3. Shows Phase Shifted

Modulation (PSM) for the proposed QCMI. The number of the ST is four in one switching period in the proposed QCMI as shown in Fig. 3, the switching frequency of inductors is the one fourth times the operating frequency. Therefore, high frequency current ripple is reduced.

To achieve a quality of output voltage as shown in Fig. 4, the capacitor voltage in each module will be the same. From (4) and (5), the capacitor voltages $V_{C A}$ and $V_{C B}$, is controlled by $S T$ duty cycle $D_{1}$ and $D_{2}$ respectively. When $D_{1}$ is different from $D_{2}$ to keep $V_{C A}=V_{C B}$ in such a case the input voltage in each module is unbalanced. The difference between $\mathrm{D}_{1}$ and $\mathrm{D}_{2}$ results in generating the $\mathrm{DC}$ offset at the output voltage.A capacitor $\mathrm{C}$ is added to the output of the inverter to remove the DC offset of the output voltage. 
T.Sakthivel, and Dr.C. Govindaraju
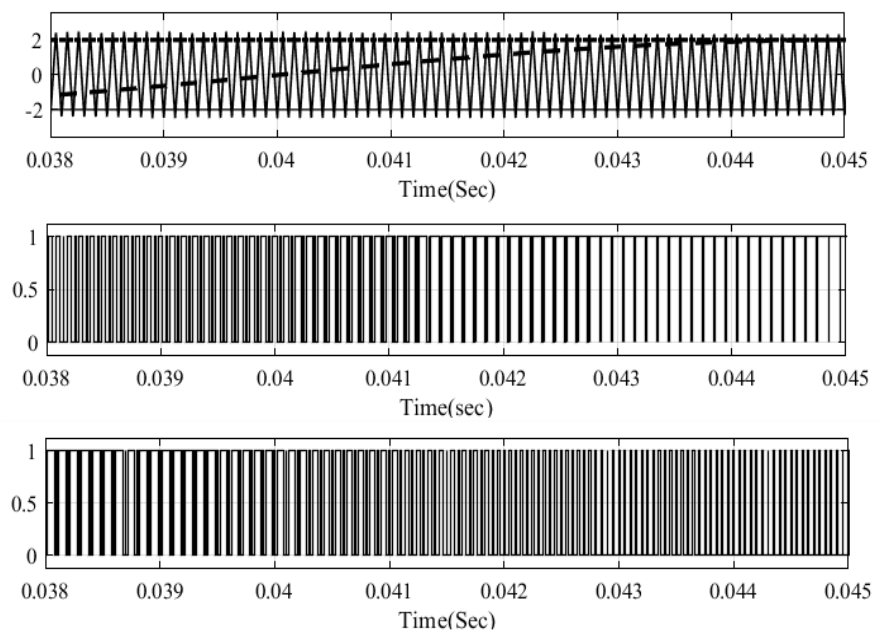

(a)
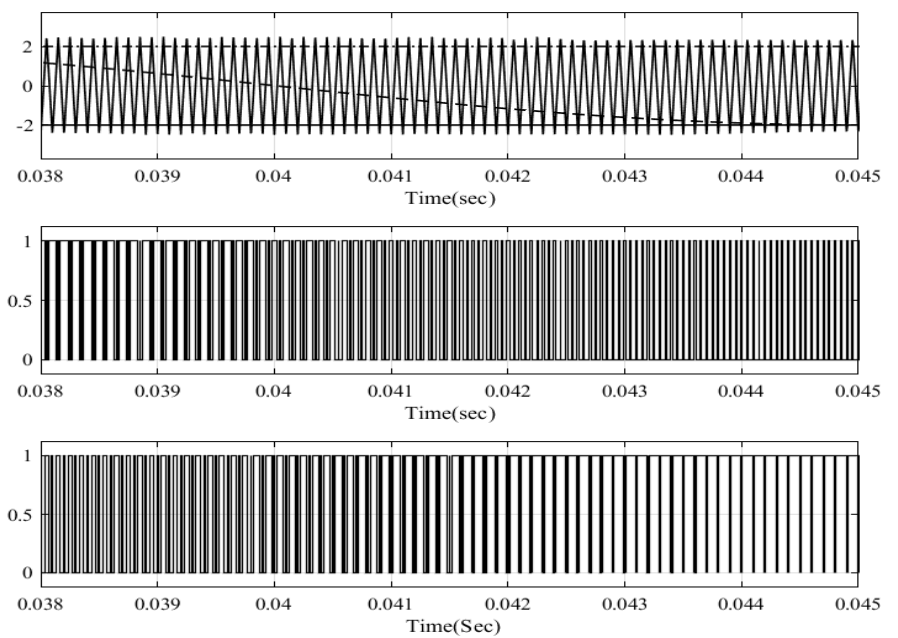

(b)
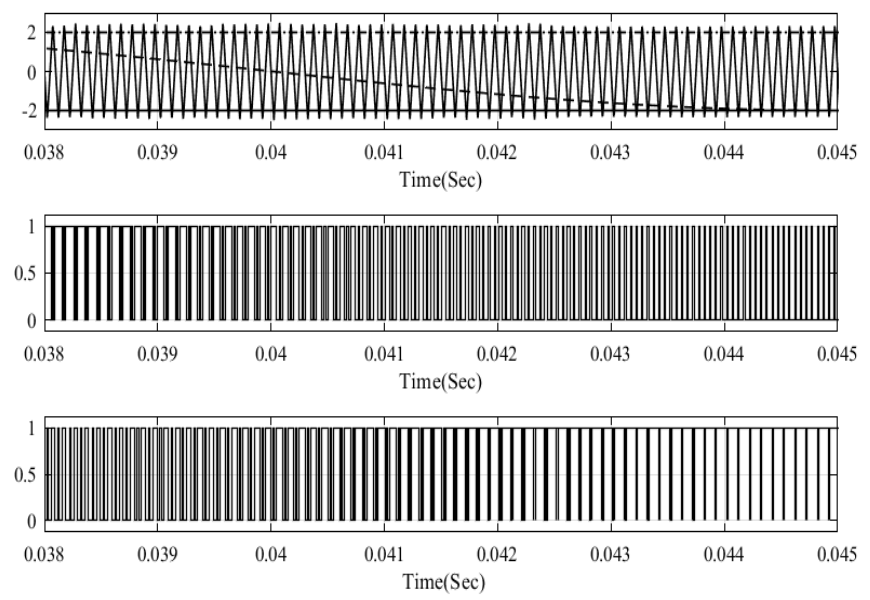

(c) 

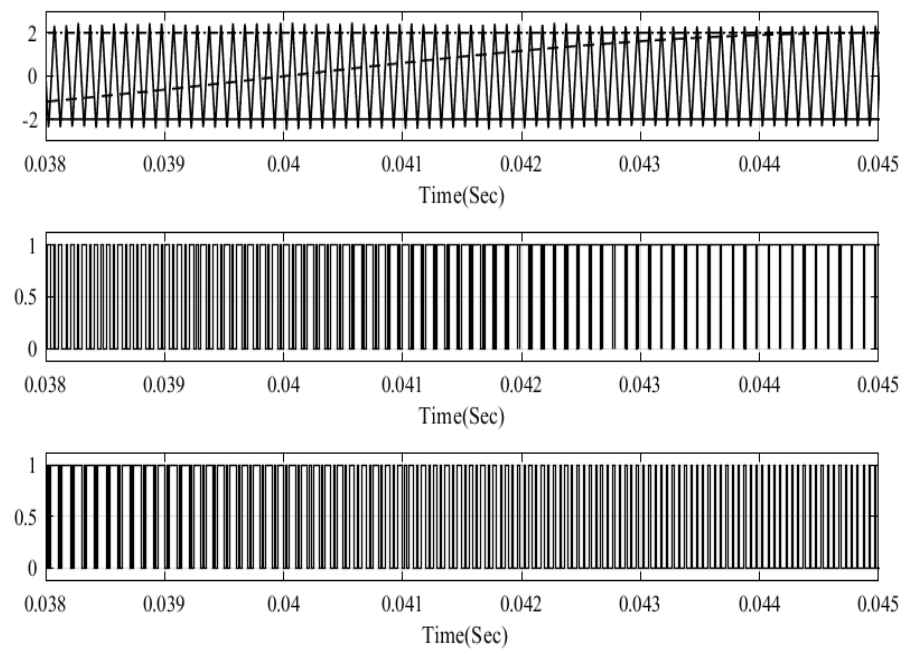

(d)

Figure 1 PWM pattern for the proposed QCMI. (a) S1 and S2 switching pattern, (b) S3 and S4 switching pattern, (c) S5 and S6 switching pattern, (d) S7 and S8 switching pattern

Fig. 1. Shows the inverter with unbalanced DC source condition, where the capacitor $C$ is connected between $b_{1}$ and $b_{2}$ at filter output. Assuming $V_{C}=V_{C A}=V_{C B}$, the DC offset voltage is calculated as

$$
V_{C}=\frac{D_{1}}{1-2 D_{1}} V_{1}-\frac{D_{2}}{1-2 D_{2}} V_{2}=\left(D_{1}-D_{2}\right) V_{C}
$$

The voltage stress on $C$ is very low because of the very low value of difference between $D_{1}$ and $\mathrm{D}_{2}$. Therefore, the size of the overall cascade system is small due to the size and cost of the capacitor $\mathrm{C}$.

\section{COMPARISON WITH CONVENTIONAL CMI}

Comparison of the passive and active components of the qCMI is shown in table 1 . The proposed inverter uses two less switches and one more capacitor in comparisons with CBFL but the CBFLI has a shoot through problem. The switching frequency is one fourthtimes the operating frequency of the full bridge circuit, while it is two times in the cascaded ZSI. As a result, the high frequency current ripple on inductors of the proposed QCMI is a half that of the cascaded ZSI.

Since, the cascaded ZSI has the same nature in shoot-through immunity as the proposed QCMI, the voltage stress comparison between two inverters is addressed. Table I compares the equations of the cascaded ZSI to the proposed QCMI. As in Table I, the capacitor voltages of the cascaded ZSI are smaller than those of the proposed inverter. However, capacitor voltage stresses in each module is same. The voltage stress on switches and diodes of the proposed inverter is same as that of the cascaded ZSI. 
Table 1 Comparison between the proposed qCMI and the Conventional Five - Level Inverters.

\begin{tabular}{|c|c|c|c|c|}
\hline S.NO & PARAMAETERS & QCMI & CascadedZSI & CBFLI \\
\hline 1. & Inductors & 2 & 4 & 2 \\
\hline 2. & Capacitors & 3 & 4 & 2 \\
\hline 3. & Diodes & 12 & 10 & 12 \\
\hline 4. & Power switches & 8 & 8 & 10 \\
\hline 5. & Shoot-through immunity & Yes & Yes & No \\
\hline 6. & Input current & Continuous & Continuous & Continuous \\
\hline 7. & Inductor frequency & $4 \mathrm{fs}$ & $2 \mathrm{fs}$ & Fs \\
\hline
\end{tabular}

\section{SIMULATION RESULTS AND ANALYSIS}

To test the performance of the proposed QCMI, MATLAB simulation model has been developed. Table II shows the simulation parameters used.

Table 2 Simulation parameters of proposed qCHB-FLI

\begin{tabular}{|c|c|}
\hline PARAMETERS & RATINGS \\
\hline Power & $1 \mathrm{kVA}$ \\
\hline Output Voltage\& Frequency & 230Vrms\& $50 \mathrm{~Hz}$ \\
\hline Inductors $\left(\mathrm{L}_{\mathrm{A}} \& \mathrm{~L}_{\mathrm{B}}\right)$ & $3 \mathrm{mH}$ \\
\hline Capacitors $\left(\mathrm{C}_{\mathrm{A}} \& \mathrm{C}_{\mathrm{B}}\right)$ & $4.7 \mathrm{mF} / 400 \mathrm{~V}$ \\
\hline $\mathrm{C}$ & $4.4 \mathrm{mF} / 25 \mathrm{~V}$ \\
\hline Inductor $\left(\mathrm{L}_{\mathrm{F}}\right)$ & $4 \mathrm{mH}$ \\
\hline Load Resistor $(\mathrm{R})$ & $40 \Omega$ \\
\hline Switching frequency $(\mathrm{fs})$ & $20 \mathrm{KHz}$ \\
\hline
\end{tabular}

All switches are assumed with $0.3 \Omega$ as on state resistance in the simulation. First, $V_{1}=V_{2}$ $=50 \mathrm{~V}$ so as to conform the properties of the balanced DC source condition. When both input voltages are the same then Fig. 4 shows the simulation results for the proposed QCMI. Fig. 4(a) shows, the five-level output voltage of the inverterand the load voltage is $230 \mathrm{~V}_{\text {rms. }}$.From Fig. $4(\mathrm{a})$, it is seen that both the capacitor $\mathrm{C}_{\mathrm{A}}$ and $\mathrm{C}_{\mathrm{B}}$ voltages are boosted to $126 \mathrm{~V}$ in the steady state and the peak to peak voltage on $\mathrm{C}_{\mathrm{A}}$ and $\mathrm{C}_{\mathrm{B}}$ capacitors is $7 \mathrm{~V}$. The square waveform of each modules of the DC link voltage is shown in Fig. 4(b).

Under unbalanced DC source condition, input voltage of modules, $\mathrm{V} 2=60 \mathrm{~V}$, while $\mathrm{V}_{1}=$ $50 \mathrm{~V}$ is considered. 
Design and Analysis of Quasi Cascaded Multi-Level Inverter

The
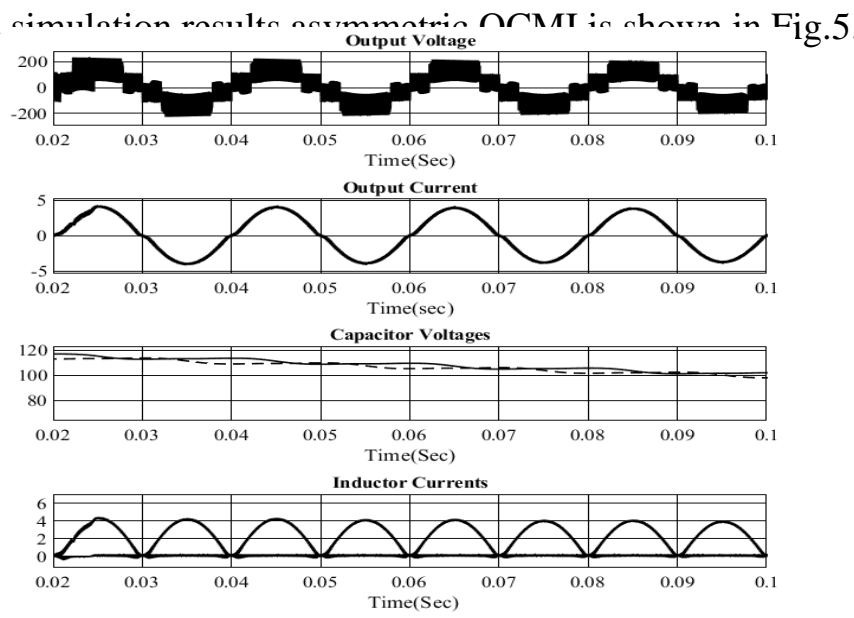

4.(a)
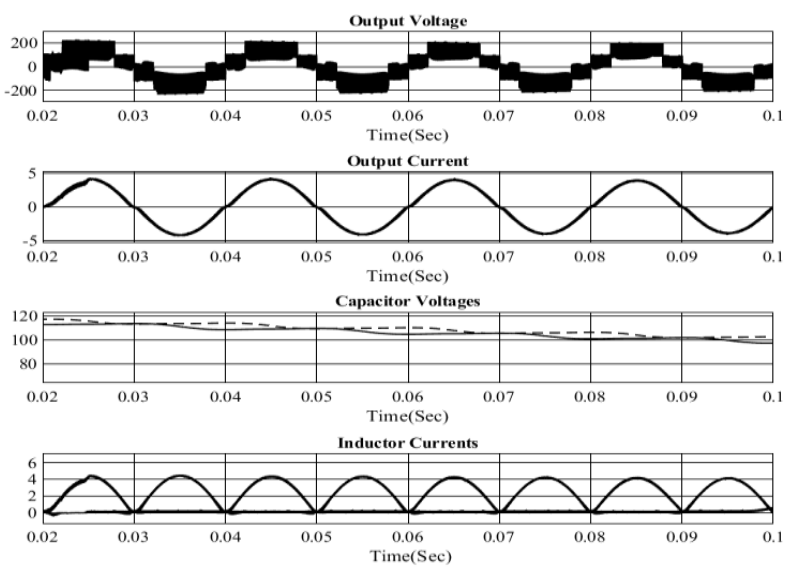

5 (a)
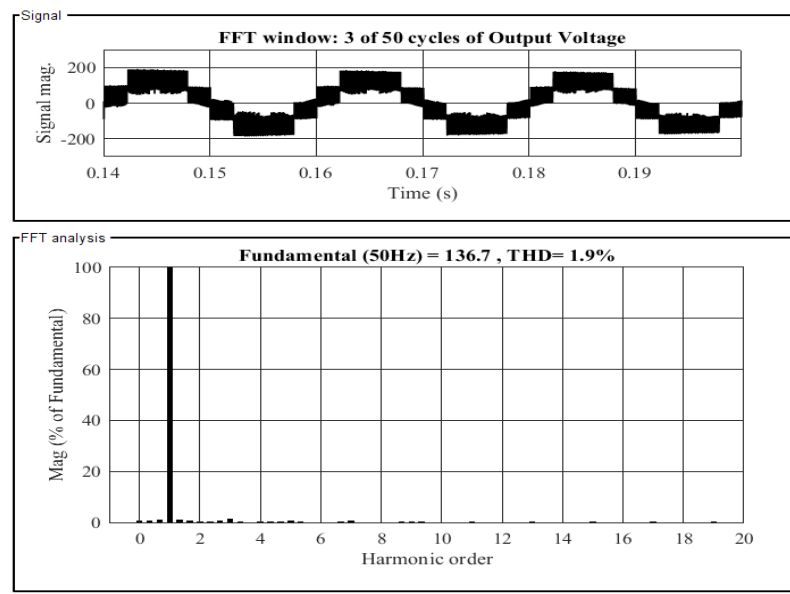

4 (b) 

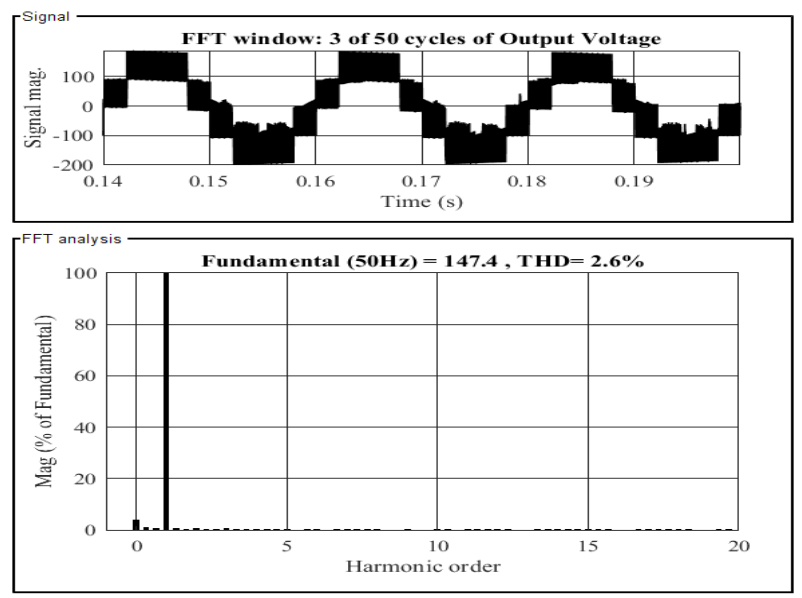

5 (b)
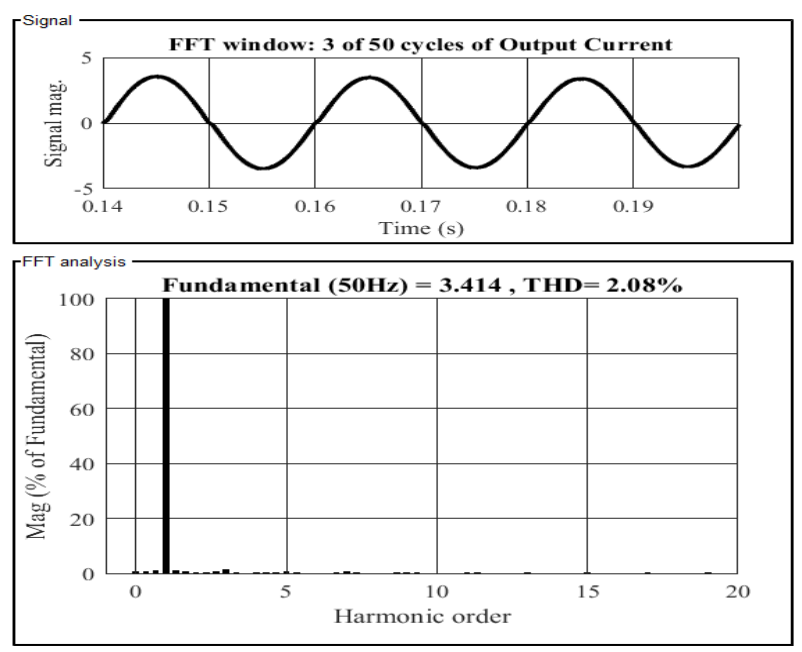

$4(\mathrm{c})$
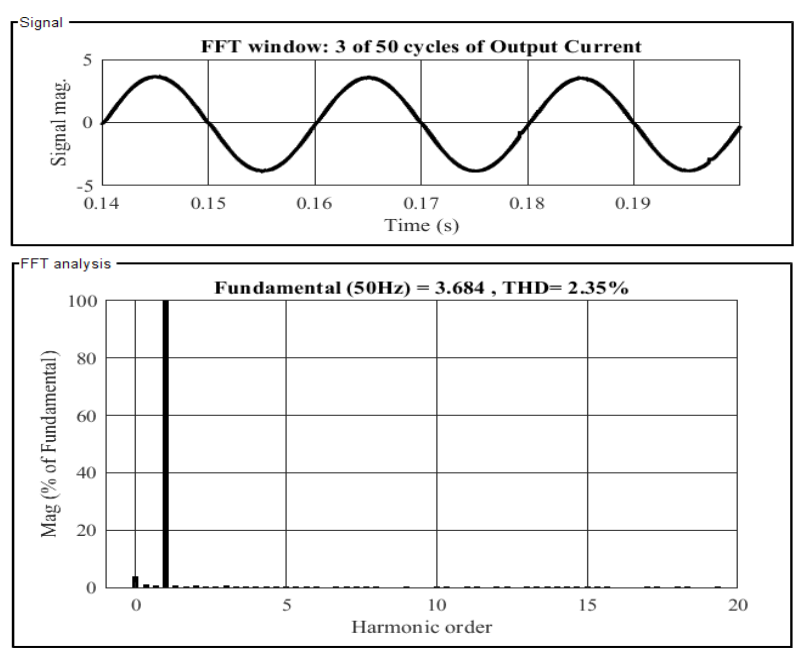

$5(\mathrm{c})$

Figure 4 (a) Simulation results for $\mathrm{V} 1=\mathrm{V} 2=50 \mathrm{~V}$ of five level output voltage, output current, inductor currents, capacitor voltages, (b) THD of Output voltage, (c) THD of uotput current.

Figure 5 (a) Simulation results for $\mathrm{V}_{1}=50 \mathrm{~V} \& \mathrm{~V}_{2}=60 \mathrm{~V}$ of five level output voltage, output current, inductor currents, capacitor voltages, (b) THD of output voltage, (c) THD of output current. 
Table 3 Output Voltage THD

\begin{tabular}{|c|c|c|c|}
\hline PARAMAETERS & QCMI & Cascaded ZSI & CBFLI \\
\hline When $\mathrm{V}_{1}=\mathrm{V}_{2}=50 \mathrm{~V}$ & 1.90 & 3.10 & 3.21 \\
\hline When $\mathrm{V}_{1}=50 \mathrm{~V} \& \mathrm{~V}_{2}=60 \mathrm{~V}$ & 2.60 & 3.50 & 3.86 \\
\hline
\end{tabular}

Table 4 Output Current THD

\begin{tabular}{|c|c|c|c|}
\hline PARAMAETERS & QCMI & Cascaded ZSI & CBFLI \\
\hline When $\mathrm{V}_{1}=\mathrm{V}_{2}=50 \mathrm{~V}$ & 2.08 & 3.40 & 3.60 \\
\hline When $\mathrm{V}_{1}=50 \mathrm{~V} \& \mathrm{~V}_{2}=60 \mathrm{~V}$ & 2.35 & 3.70 & 3.90 \\
\hline
\end{tabular}

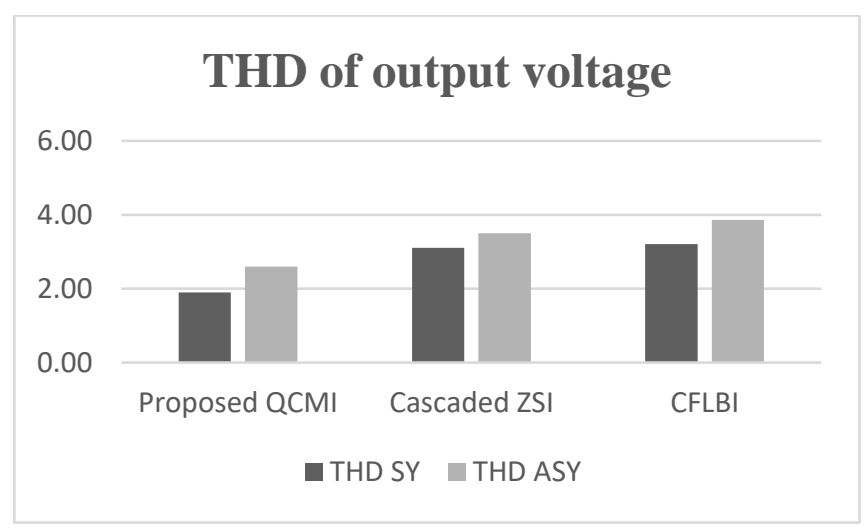

(a)

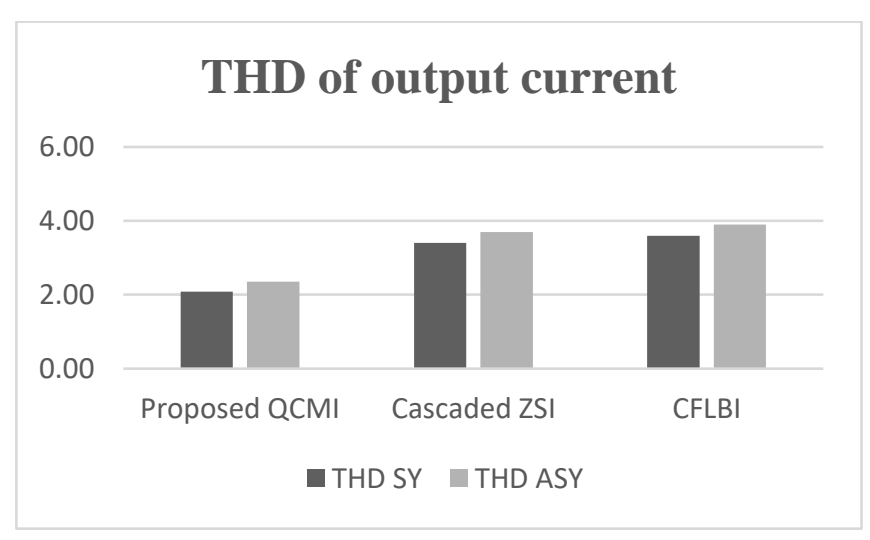

(b)

Figure 5 (a) THD in Output voltage, (b) THD in output current.

The output voltage of the proposed inverter has five levels and the load voltage is $230 \mathrm{~V}_{\text {rms }}$ as shown in Fig 5(a). From Fig. 5(a), both the capacitor $C_{A}$ and $C_{B}$ voltages are also boosted to $126 \mathrm{~V}$ in the steady state, and the peak-to-peak voltage on $\mathrm{C}_{\mathrm{A}}$ and $\mathrm{C}_{\mathrm{B}}$ capacitors are $7 \mathrm{~V}$. The average value of the capacitor $C$ filter voltage is very low, about $7 \mathrm{~V}$.

The total size and weight of proposed inverter is not affected as the size of the capacitor filter as small. The square waveform as shown in Fig. 5(b) for the DC link voltage of each module. Because the ST duty cycle of module B is smaller than that of module A, there are high distortion in the positive half cycle of the five-level output as shown in Fig. 5(a). When the ST 
duty cycle of module $\mathrm{A}$ is higher than that of module B the five-level output voltage has a lower distortion in the negative half cycle.

THD analysis of the output current and voltage between the cascaded ZSI, CFLBI and the proposed QCMI is shown in Table III and IV.It canbe observed from Table III and IV that the THD of the output current andvoltage of the proposed inverter is lower than that of the cascaded ZSI.

\section{CONCLUSION}

A single-phase QCMI five-level inverter with boost voltage ability is proposed here. The features of the proposed inverter are as follows: Output voltage in five levels, reduced number of passive components and shootthrough immunity. Enhanced rejection of disturbance with good performance can be achieved by using PI controller maintaining constant voltage at capacitor.Circuit analysis and its PWM control strategy for the proposed system was discussed. Simulation results are shown to validate the proposedQCMI. Number of full Bridge modules can be added to increase the levels of output voltage, thus increasing the reliability and modularity of the converter. The proposedinverter can be used in distributed generation with more DC sources and grid integrated PV systems.

\section{REFERENCES}

[1] S. Kouro, M. Malinowski, K. Gopakumar, J. Pou, L. G. Franquelo, B. Wu, J. Rodriguez, M. A. Pérez, and J. I. Leon, "Recent advances and industrial applications of multilevel converters," IEEE Trans. Ind. Electron., 57(8), 2010, 2553- 2580.

[2] M. Malinowski, K. Gopakumar, J. Rodriguez, and M. A. Pérez, "A survey on cascaded multilevel inverters," IEEE Trans. Ind. Electron., 57(7), 2010, 2197-2206.

[3] E. Villanueva, P. Correa, J. Rodríguez, and M. Pacas, "Control of a single-phase cascaded H-bridge multilevel inverter for grid-connected photovoltaic systems," IEEE Trans. Ind. Electron., 56(11), 2009, 4399-4406.

[4] F. Khoucha, S. M. Lagoun, K. Marouani, A. Kheloui, and M. E. H. Benbouzid, "Hybrid cascaded H-bridge multilevel-inverter induction-motor-drive direct torque control for automotive applications,” IEEE Trans. Ind. Electron., 57(3), 2010, 892- 899.

[5] R. Uthirasamy, U. S. Ragupathy, V. K. Chinnaiyan, and C. Megha, "Experimentation of boost chopper interfaced cascaded multilevel inverter topology for photo voltaic applications," Int. Rev. Electr. Eng.,9(1), 2014, 16-25.

[6] A. Mora, J. Juliet, A. Santander, and P. Lezana, "Dead-time and semiconductor voltage drop compensation for cascaded H-bridge converters," IEEE Trans. Ind. Electron., 63(12), 2016, 7833-7842.

[7] D. Sun, B. Ge, X. Yan, D. Bi, H. Zhang, Y. Liu, H. Abu-Rub, L. Ben-Brahim, and F. Z Feng., "Modeling, impedance-design, and efficiency analysis of quasi-Z source module in cascaded multilevel photovoltaic power system," IEEE Trans. Ind. Electron., 61(11), 2014, $6108-6117$.

[8] Y. Liu, B. Ge, H. Abu-Rub, and F. Z. Peng, "An effective control method for three-phase quasi-Z-source cascaded multilevel inverter-based grid-tie photovoltaic power system," IEEE Trans. Ind. Electron., 61(12), 2014, 6794 - 6802.

[9] D. Sun, B. Ge, W. Liang, H. Abu-Rub, and F. Z. Peng, "An energy stored quasi-Z-source cascade multilevel inverter-based photovoltaic power generation system," IEEE Trans. Ind. Electron., 62(9), 2015, 5458 - 5467.

[10] M. Aleenejad, H. Mahmoudi, and R. Ahmadi, "A fault-tolerant strategy based on fundamental phase-shift compensation for three-phase multilevel converters with quasi-Z- 
source networks with discontinuous input current," IEEE Trans. Power Electron, 31(11), 2016, $7480-7488$.

[11] M. R. Banaei, A. R. Dehghanzadeh, A. Fazel, and A. B. Oskouei, "Switching algorithm for single Z-source boost multilevel inverter with ability of voltage control," IET Power Electron., 6(7), 2013, 1350 - 1359.

[12] C. Liu, P. Sun, J. Lai, Y. Ji, M. Wang, C. Chen, and G. Cai, "Cascaded dual-boost/buck active-front end converter for intelligent universal transformer," IEEE Trans. Ind. Electron., 59(12), 2012, 4671-4680.

[13] M. K. Nguyen, Y. C. Lim, J. H. Choi and G. B. Cho, "Isolated high step-up dc-dc converter based on quasi-switched-boost network," IEEE Trans. Ind. Electron., 63(12), 2016, 75537562 . 